\title{
Effect of increasing ligand length on the structure of silver complexes $\dagger$
}

\author{
Fabienne Gschwind*ab and Katharina M. Fromm*a
}

\begin{abstract}
A new series of ligands in which nicotinic acid was linked to different monomethyloligoethers and their corresponding silver complexes were prepared. The crystal structures of the silver compounds were investigated to determine the effect of increasing flexibility of the ligands on coordination to the metal ion and crystal packing. We observed the formation of one-dimensional coordination polymers for the shortest ligand derived from monoethylene glycol, the formation of stacks for the diethyleneglycol-based ligand with silver triflate, and even a helical structure for the triethylene-glycol-derived ligand complex. The three ligands, $\left(\left[\mathrm{C}_{9} \mathrm{H}_{11} \mathrm{O}_{3} \mathrm{~N}\right](\mathbf{L 1}),\left[\mathrm{C}_{11} \mathrm{H}_{15} \mathrm{O}_{4} \mathrm{~N}\right](\mathbf{L 2})\right.$, and $\left.\left[\mathrm{C}_{13} \mathrm{H}_{19} \mathrm{O}_{5} \mathrm{~N}\right](\mathbf{L} 3)\right)$, and the four new complexes, $\left[\mathrm{Ag}(\mathrm{L} 1)_{2}\left(\mathrm{NO}_{3}\right)\right](\mathbf{1}),\left[\mathrm{Ag}(\mathrm{L} 1)_{2}\left(\mathrm{SO}_{3} \mathrm{CF}_{3}\right)\right](\mathbf{2}),\left[\left(\mathrm{Ag}(\mathrm{L} 2)_{2}\left(\mathrm{SO}_{3} \mathrm{CF}_{3}\right)\right](\mathbf{3})\right.$, and $\left.\left[\mathrm{Ag}(\mathrm{L} 3)_{2}\right] \mathrm{PF}_{6}(\mathbf{4})\right)$, are presented in this paper along with an analysis of their structural features.
\end{abstract}

\section{Introduction}

For the construction of coordination compounds, $\mathrm{d}^{10}$ metals $(\mathrm{Ag}, \mathrm{Cu})$ are widely used because their flexible coordination sphere allows the generation of various supramolecular structures with ligands containing nitrogen, oxygen, and/or sulfur donor atoms. ${ }^{1}$ Polymeric coordination network synthesis is a method of construction in which the final architecture depends on the building blocks (organic ligands, metal ions, counter ions, solvent molecules) and on the interactions of self-assembled building blocks (metal ion coordination, hydrogen bonding interactions, $\pi$-interaction and metal-metal interactions).

Silver is a well-studied metal ion for such synthesis. Silver(I) has a very flexible coordination sphere, which enables it to adopt coordination numbers from 2 to 6 , resulting in its coordination sphere ranging from linear to octahedral, respectively. $\operatorname{Ag}(\mathrm{I})$ is a soft Lewis acid that has a general coordination preference for donor atoms in the order $\mathrm{S}>\mathrm{N}>\mathrm{O}^{2}$ and prefers to form simple linear chain motifs. ${ }^{3}$ It is well known that coordination polymers derived from $\operatorname{Ag}(\mathrm{I})$ with $\mathrm{N}$-donor ligands generate simple onedimensional (1D) motifs when two-coordinate metal ions react with "linear" bidentate ligands, for example, with a 4,4'-bipyridine-type ligand. ${ }^{4}$ The $1 \mathrm{D}$ coordination polymers produced by this reaction are either simple chains or double chains with metal-metal interactions that are commonly supported by bridging anions. The formation of a particular supramolecular

${ }^{a}$ University of Fribourg, Chemin du Musée 9, 1700 Fribourg, Switzerland. E-mail: katharina.fromm@unifr.ch; Fax: +4126300 9738; Tel: +41263008732

${ }^{b}$ Current location: Max Planck Institute for Solid State Research, Heisenbergstrasse 1, 70569 Stuttgart, Germany.

E-mail: f.gschwind@fkf.mpg.de; Fax:+49711689-1502;

Tel: +497116891409 array may be strongly dependent on the counter ion, and some of these arrays, including $N$-donor-derived ligands, contain a combination of functional groups such as pyridyl-oxadiazole, ${ }^{5}$ pyridyl-thioether, ${ }^{6}$ pyridyl-urea, ${ }^{7}$ pyridyl-glycol, ${ }^{8}$ or pyridylsulfur. ${ }^{9}$

The Fromm group has thoroughly investigated semi-rigid ligands derived from (iso)nicotinic acid and polyethylene glycol (Scheme 1), and a number of new structures have been reported as a result of these investigations. ${ }^{10}$ Most of these compounds are infinite polymer networks arranged in chains, double chains or layers that stack through $\pi-\pi, \pi-\mathrm{Ag}^{+}$, and other non-covalent interactions.

To investigate the different factors that influence the formation of a particular crystal structure, different sized chain spacers were used and several counter ions and solvents were tested $\left(\mathrm{NO}_{3}{ }^{-}, \mathrm{PF}_{6}{ }^{-}, \mathrm{ClO}_{4}{ }^{-}\right.$, and $\left.\mathrm{SO}_{3} \mathrm{CF}_{3}{ }^{-}\right)$.

It has been demonstrated ${ }^{11}$ that silver complexes with $\mathrm{Ag}-\mathrm{N}$, $\mathrm{Ag}-\mathrm{S}$, or $\mathrm{Ag}-\mathrm{O}$ bonds have antibacterial activity; ${ }^{12}$ these complexes have been used worldwide to treat a variety of conditions for hundreds of years. For example as treatment against biofilms, which is a well-developed bacterial survival strategy against pharmacological agents and host defenses. ${ }^{13}$

Our group has investigated the use of coordination polymer compounds of $\mathrm{Ag}(\mathrm{I})$ as antibacterial compounds for dip-coated surfaces for implants and medical devices, based on biocompatible building blocks. ${ }^{9,10,14}$ Most of these infinite coordination polymers are promising candidates for surface modification

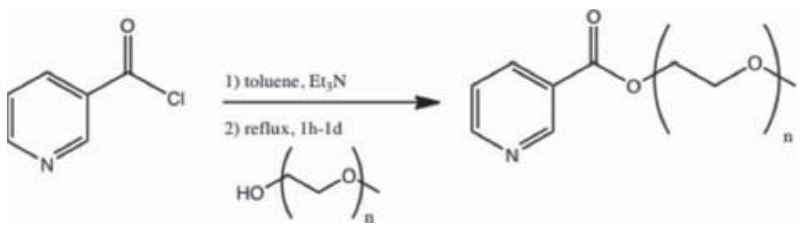

Scheme 1 General reaction scheme $(n=1,2,3)$. 
because they exhibit i) high structural stability, ii) little decomposition upon light exposure, and iii) low solubility in aqueous media. They have been shown to have good antimicrobial properties against both Gram-positive and Gramnegative bacteria. ${ }^{15,16}$

In this paper, we present three new asymmetric ligands that form interesting Ag-complexes and can potentially act as precursors for silver coatings using the MO-CVD method as coating technique. In our previous study on $\mathrm{Cu}(\mathrm{I})$ complexes, ${ }^{10 c}$ multitopic ligands based on nicotinic acid and monomethyl ethyleneglycols were developed because they i) allow multiple coordination sites, ii) demonstrate low sensitivity and low hazard, and iii) have a straightforward synthesis procedure and can be scaled up. Here, we present the coordination of three ligands, $\left(\left(\mathrm{C}_{9} \mathrm{H}_{11} \mathrm{O}_{3} \mathrm{~N}\right)[\mathbf{L 1}],\left(\mathrm{C}_{11} \mathrm{H}_{15} \mathrm{O}_{4} \mathrm{~N}\right)[\mathbf{L} 2]\right.$, and $\left(\mathrm{C}_{13} \mathrm{H}_{19} \mathrm{O}_{5} \mathrm{~N}\right)$ [L3]), in which the ethylene glycol chain length is increased step by step, and their coordination with $\operatorname{Ag}(\mathrm{I})$ salts.

\section{Results}

\section{Nicotinic-acid-functionalized monomethyl polyethylene glycol derivatives $\left(\mathrm{C}_{9} \mathrm{H}_{11} \mathrm{O}_{3} \mathrm{~N}\right)$ [L1], $\left(\mathrm{C}_{11} \mathrm{H}_{15} \mathrm{O}_{4} \mathrm{~N}\right)$ [L2], and $\left(\mathrm{C}_{13} \mathrm{H}_{19} \mathrm{O}_{5} \mathrm{~N}\right)[\mathrm{L} 3]$}

Monomethyl polyethylene glycol ligands were designed as an alternative to bisnicotinate ligands, which were studied previously. ${ }^{10}$ Owing to the flexibility of the ligand chain, it can be assumed that the ligand has a series of different coordination behaviors dependent on the solvent, chain length, metal ion, and counter ion. Therefore, the influence of these systems on the coordination of different silver salts was investigated.

The method for synthesis of this type of ligand is straightforward. After chlorination of the nicotinic acid, the acid chloride is coupled with monomethyl glycol (Scheme 1). All products of this series are liquids at room temperature.

\section{Crystal structure of $\left[\mathrm{Ag}(\mathrm{L1})_{2}\left(\mathrm{NO}_{3}\right)\right][1]$}

After the reaction of silver nitrate with L1, colorless crystals of $\left[\mathrm{Ag}(\mathrm{L} 1)_{2}\left(\mathrm{NO}_{3}\right)\right](\mathbf{1})$ can be obtained via slow evaporation. $\mathbf{1}$ crystallizes in the triclinic space group $P \overline{1}$. The asymmetric unit consists of a silver cation that is connected to two crystallographically independent ligands and the nitrate anion (Fig. 1).

The silver cations are connected into a linear zig-zag chain by O,O-chelating nitrate anions with Ag1-O8 2.692(6) ^ and Ag1O9 2.765(1) A. Perpendicular to this chain propagation, the two

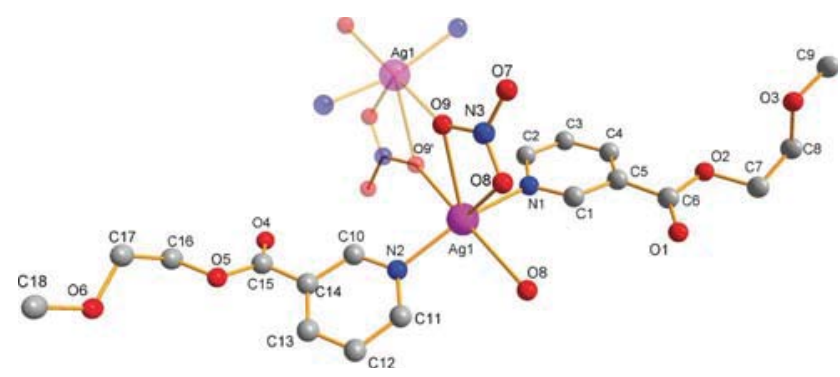

Fig. 1 Numbered representation of $\mathbf{1}$, indicating the connectivity between the asymmetric units, i) $1+x, y, z$ ii) $2-x,-y,-z$ (hydrogen atoms are omitted for clarity). ligands bind with $\mathrm{Ag}-\mathrm{N}$ distances of $c a .2 .18 \AA$ and the $\mathrm{N}-\mathrm{Ag}-\mathrm{N}$ angle of $c a .160 .9^{\circ}$. The ethylene chain adopts a gauche conformation (torsion angles $\mathrm{O} 2-\mathrm{C} 7-\mathrm{C} 8-\mathrm{O} 3 \quad 68.55^{\circ}$ and $\mathrm{O} 5$ C16-C17-O6 $82.45^{\circ}$ ) (Fig. 2). The N-O distances within the

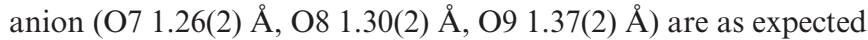
longer for the coordinating $\mathrm{O}$-atoms as compared to the terminal O7.

In the packing of $\mathbf{1}, \mathrm{O} 7$ of the nitrate group forms short contacts with the $\mathrm{H}$-atoms of $\mathrm{C} 7$ and $\mathrm{C} 17$ of the neighbor glycol chains (O7-H7A 2.50(1) $\AA$ and O7-H17A 2.42(2) $\AA$ ). In the $x$-direction, a pseudo-metallacycle structure obtained by short contacts is visible (Fig. 2). The chains of 1 pack tilted to each other along the $y$-direction, and stacks of those ribbons contact each other via the polyether chains and $\pi$-stacking interactions. The $\delta-\delta$ interactions between the head-to-head arranged ligands lead to centroid-centroid distances between parallel pyridine rings of $3.804 \AA$ for the two rings, with the parallel planes being $3.45 \AA$ apart and offset by $2.38 \AA$. This provides a more efficient attraction between the ribbon stacks.

The packing of compound $\mathbf{1}$ along the $x$-axis is reminiscent of the packing of metallacycles obtained using a symmetric ligand in which diethyleneglycol is substituted by two isonicotinic acid moieties ${ }^{14}$ (Fig. 3).

\section{Crystal structure of $\left[\mathrm{Ag}(\mathrm{L1})_{2}\left(\mathrm{SO}_{3} \mathrm{CF}_{3}\right)\right][2]$}

Ligand $\mathbf{L 1}$ was also tested with silver triflate. While the silver ion is also coordinated to two ligands (see compound 1), the different counter ion causes structural changes, which will be described below.

Following crystallization of a solution of silver triflate with the ligand L1, colorless crystals of $\left[\mathrm{Ag}(\mathrm{L} 1)_{2}\left(\mathrm{SO}_{3} \mathrm{CF}_{3}\right)\right]$ (2) are obtained. The compound crystallizes in the triclinic space group
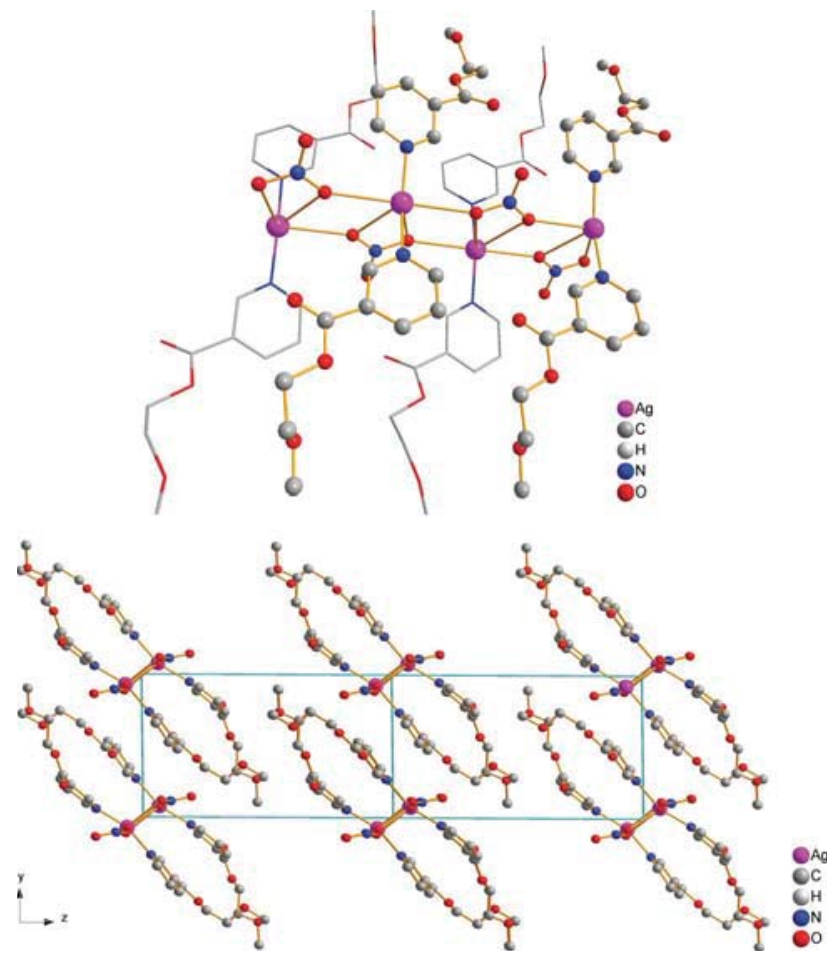

Fig. 2 1D coordination polymer of $\mathbf{1}$ and packing along the $x$-axis. 


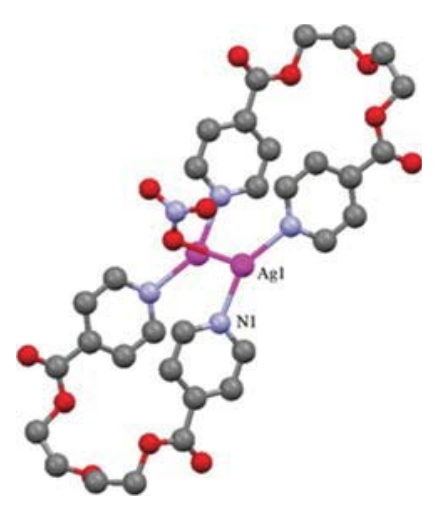

Fig. 3 The metallacycle of Ag with an isonicotinic acid diethylene glycol chain shows an arrangement of the polyethylene glycol chains that is very similar to those of complex 1 with free monomethyl ethylene glycols (hydrogen atoms and one nitrate are omitted for clarity).

$P \overline{1}$. Two ligands connect via the nitrogen atom of the nicotinic group to the silver cation, forming an angle of $c a .171 .92^{\circ}$ and Ag- $\mathrm{N}$ distances of $2.14 \AA$ on average (reported values range from 1.9 to $2.8 \AA$ ). ${ }^{17}$ The triflate counter ion connects via $\mathrm{O} 8$ and O9 to Ag1 (Fig. 4).

The triflate ion also connects to the next silver ion via Ag1-O8 and Ag1-O9, forming dimers, which are connected via hydrogen bridges $(\mathrm{O} 7-\mathrm{H} 3)$ to the next dimer (Fig. 5). The anions are then arranged alternatingly above and below that chain.

2 contains a $\mathrm{Ag}-\mathrm{Ag}$ contact, which can be considered a weak interaction at a distance of 3.24(6) $\AA$ ). ${ }^{18}$ The distance between the pyridine rings of parallel ligands is around $3.75 \AA$ between the centroids or $3.38 \AA$ if measured between the parallel ring planes. Different from the formation of pseudo-metallacycle in compound $\mathbf{1}$, this compound forms rows of $1 \mathrm{D}$ polymers that are intercalated between each other (Fig. 6).

This might be a result of phase separation between the more organic, less hydrophilic parts and the more ionic part of the structure. There are indeed short contacts between neighbor chains of the ethylene glycol (C16-O3, C18-O6, and C18-O1). Such intercalated comb-like structures are indeed known from<smiles></smiles>

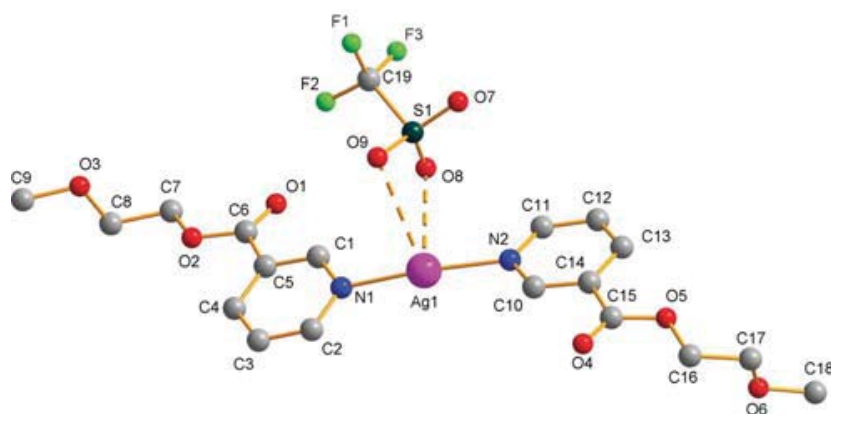

Fig. 4 Schematic drawing and numbered plot of one unit of 2.

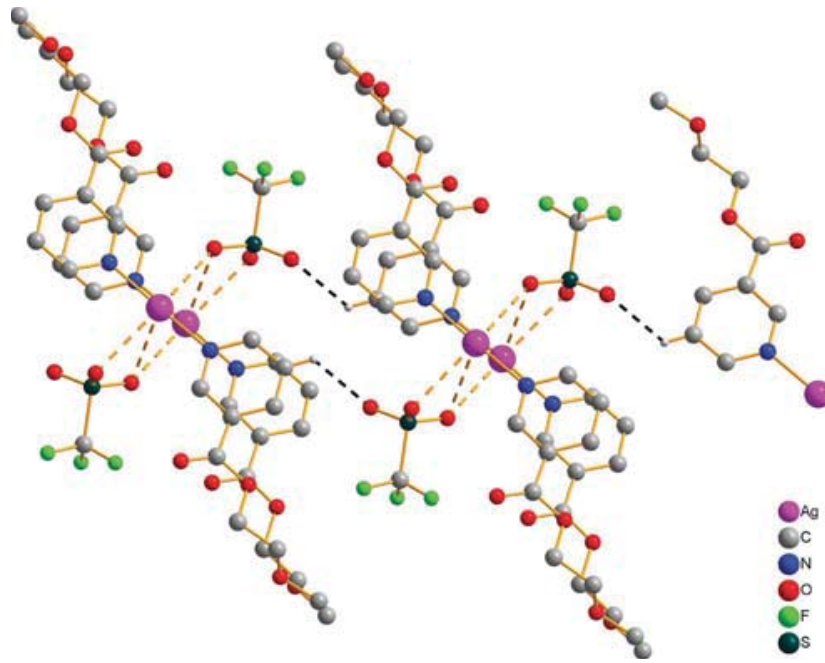

Fig. 5 Dimer via the triflate anion and further connections via hydrogen bonds (the black dash lines show the hydrogen bond and the brown dash lines shows the Ag-O coordination).

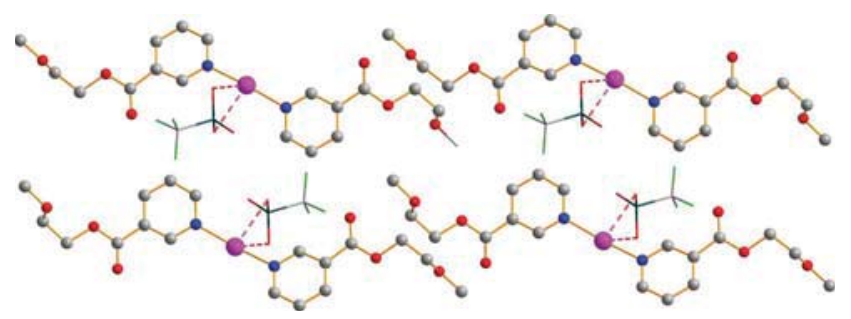

Fig. 6 Intercalation of the ethyleneglycol chains ( $\mathrm{H}$ atoms are omitted for clarity).

the literature. ${ }^{19}$ The so-formed sheet-like structure stacks on top of each other with the fluorine atoms pointing towards each other (Fig. 7). Packing in the $y$-direction shows the arrangement along the rows of molecules (supporting material is presented in Fig. S1, ESI). $\dagger$

\section{Crystal structure of diethylene glycol monomethyl silver triflate $\left[\mathrm{Ag}(\mathrm{L2})_{2}\left(\mathrm{SO}_{3} \mathrm{CF}_{3}\right)\right][3]$}

After the successful synthesis of silver coordination compounds with L1, we synthesized compounds with the larger ligand L2. The reaction of silver triflate and $\mathbf{L} \mathbf{2}$ affords colorless crystals of $\left[\mathrm{Ag}(\mathrm{L} 2)_{2}\left(\mathrm{SO}_{3} \mathrm{CF}_{3}\right)\right](3)$ after slow evaporation. 3 crystallizes in the triclinic space group $P \overline{1}$.

The asymmetric unit consists of a silver cation connected to two ligands and one triflate anion. These building blocks arrange such that the flexible side chains of the ligands lie on the same side of the molecule, embracing the central triflate anion (Fig. 8).

The $\mathrm{Ag}-\mathrm{N}$ distances are $c a .2 .15 \AA$ long, with an $\mathrm{N}-\mathrm{Ag}-\mathrm{N}$ angle of $c a \cdot 166.4^{\circ}$. The triflate anion binds in a monodentate fashion only via O9 at 2.684(2) $\AA$, which is as expected shorter than in $\mathbf{2}$ due to the terminal binding mode of the anion in $\mathbf{3}$. A hydrogen bond between the methyl group $\mathrm{C} 11$ and F1 (ca. $3 \AA$ ) can also be observed.

The ethylene glycol chains are not coplanar; rather, one chain is pointing above, while the other points below the mean plane formed by the silver ion and the two pyridine rings, leading to a 


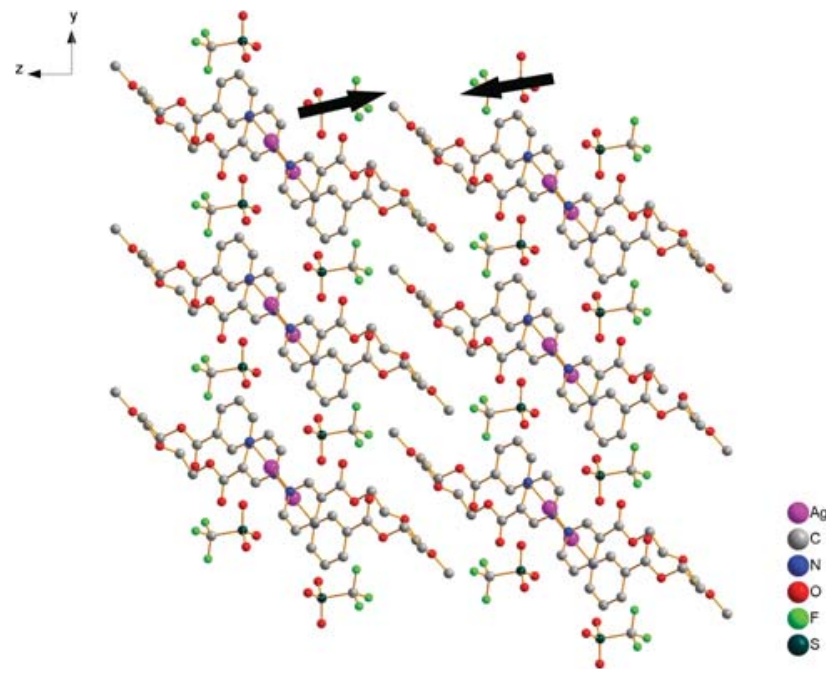

Fig. 7 Stacks of dimer of compound 2, with the triflate molecules pointing to each other, a visualization is given by two black arrows (view along the $x$-direction).

motif resembling the start of a helix. In the $z$-direction, the next molecules lie slightly shifted over the first complex, but in a headto-tail arrangement (Fig. 9). The distance between both silver atoms is about $3.4 \AA$, while that between the centroids of the pyridine rings is $3.82 \AA$, with an offset of $1.34 \AA(\mathrm{C}-\mathrm{H}-\pi$ contacts between $\mathrm{H} 1$ and a pyridine ring are observed at $c a$. $2.7 \AA$ ). These findings indicate that there is a $\pi-\pi$-interaction (Fig. 9).

The packing in the $x$-direction forms stacks (Fig. 10). In the $y$-direction, a formation of rows or even more columns can be observed (ESI, Fig. S2).

Crystal structure of triethylene glycol monomethyl ether nicotinate silver hexafluorophosphate $\left[\mathrm{Ag}(\mathrm{L} 3)_{2}\right] \mathrm{PF}_{6}[4]$

The smaller ligands ( $\mathbf{L} 1$ and $\mathbf{L 2}$ ) could be coordinated to a silver cation. In both cases, the silver cation was only coordinated by the $\mathrm{N}$-donor functions.

When $\mathrm{AgPF}_{6}$ is reacted with $\mathbf{L 3}$ in ethanol, crystals of $\left[\mathrm{Ag}(\mathrm{L} 3)_{2}\right] \mathrm{PF}_{6}(4)$ are obtained. 4 crystallizes in the centrosymmetric,

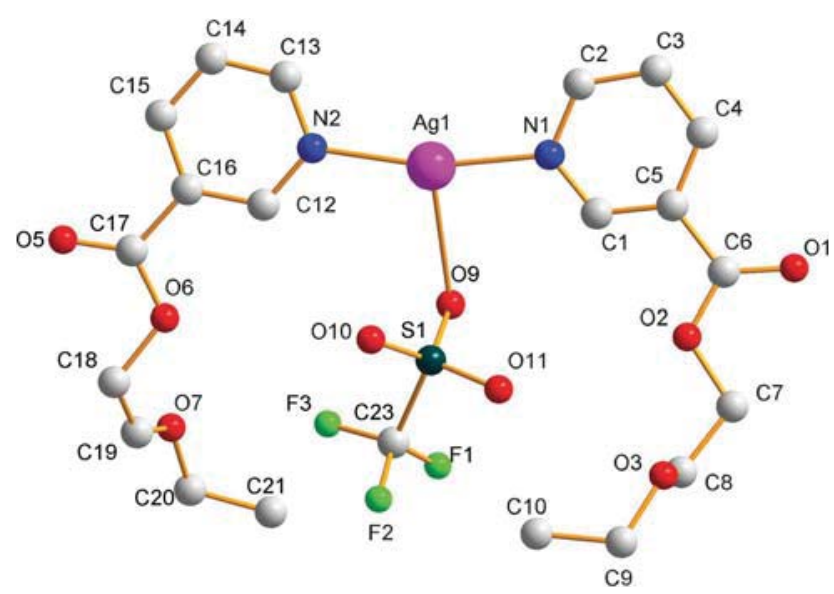

Fig. 8 Representation of $\mathbf{3}$ (hydrogen atoms are omitted for clarity and also the terminal $\mathrm{O}-\mathrm{Me}$ group, to avoid overlapping).

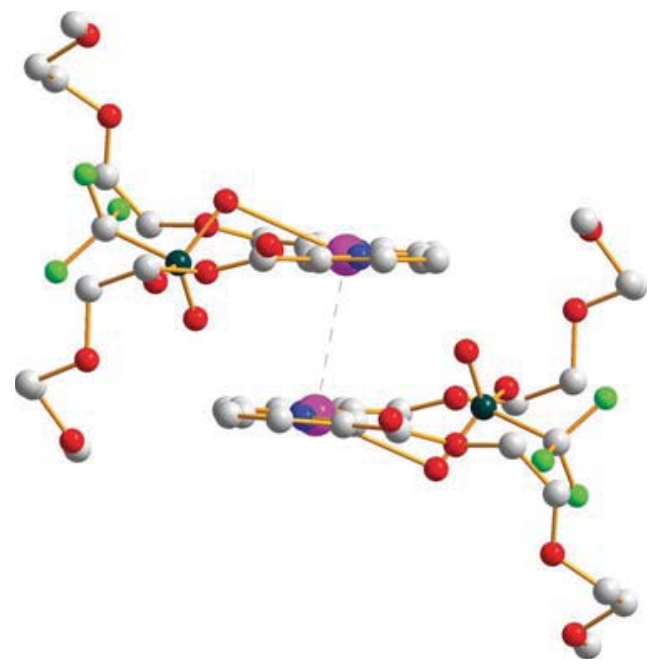

Fig. 9 Dimer formation of complex 3, the dash line shows the $\pi$ $\pi$-interaction.

monoclinic space group $C 2 / c$. The unit cell consists of half of a $\mathrm{PF}_{6}$ anion, lying on a twofold axis and a complete molecule of $\mathbf{L} \mathbf{3}$ coordinated with the $N$-terminus to half of a silver ion (Fig. 11).

The coordination of one ligand molecule of $\mathbf{L} \mathbf{3}$ to the silver ion occurs first via the nitrogen donor atom (ca. 2.16 ̊). However, in contrast to compounds $\mathbf{1 - 3}$ based on $\mathbf{L 1}$ and $\mathbf{L 2}$, a second ligand $\mathbf{L 3}$ now wraps around the silver ion via three oxygen atoms of the ethylene glycol chains at rather long distances (on average $3.14 \AA$ ), this could be due to the long chains of the ligand, which allow a different flexible arrangement. The coordination number of the silver ions is eight $(2+6)$, which is high compared to previous Ag complexes. By symmetry, each silver ion is thus coordinated in a perfectly linear fashion by two ligands L3, while two more ligands bind loosely to the same metal ion via the glycol chains. As a result, two L3 ligands are arranged next to each other in an offset, head-to-tail fashion. At the other end of these two ligands, the polyether chain of the first ligand and the nitrogen atom of the second ligand bind to the next silver ion. Two other ligands bind to this silver ion, leading to a $1 \mathrm{D}$ helical arrangement (Fig. 12).

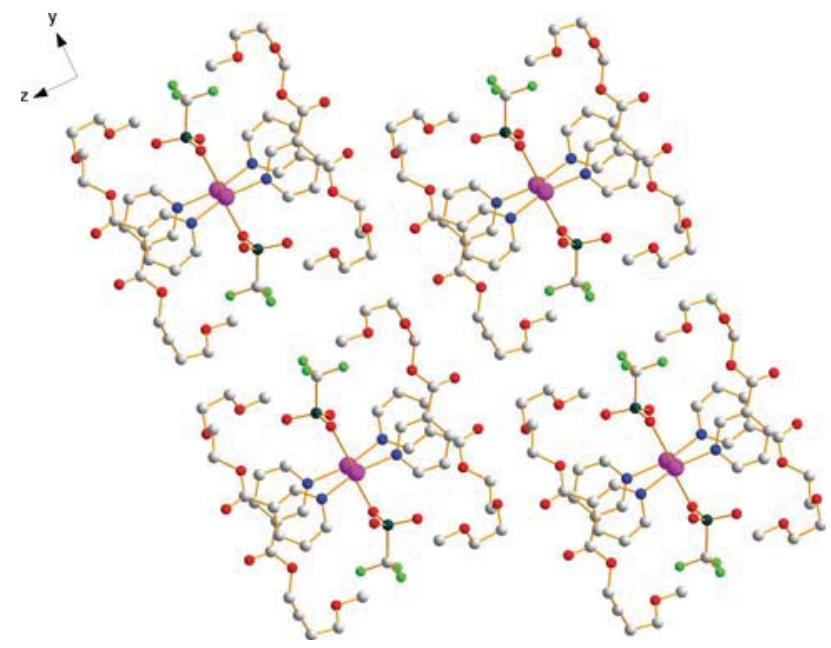

Fig. 10 Packing in the $x$-direction, formation of stacks. 


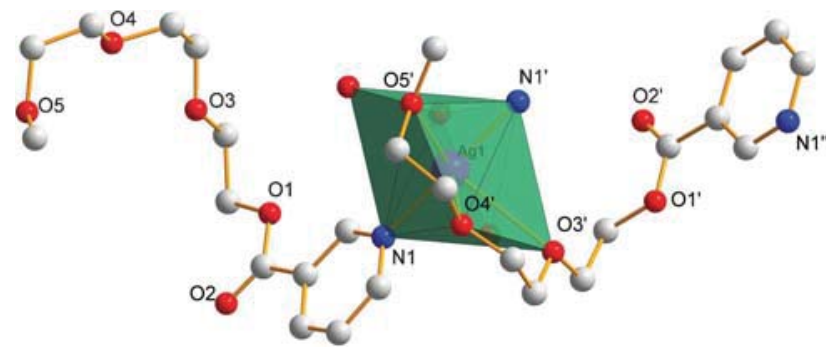

Fig. 11 Extended molecule of 4, i) $x,-y, 0.5+z$ (hydrogen atoms and the counter ion are omitted for clarity).

Alternatively, the structure can be explained as follows: complexes of silver ions to which two ligands bind via the $\mathrm{N}$-atoms in a linear fashion are arranged into chains such that the polyether chains of their ligands can wrap around the silver ions of their neighbor complexes. The polyether chains then act as equatorial ligands with a total of six O-donor atoms, similar to an open crown ether moiety, while the nitrogen atoms are in axial positions.

This coordination is likely a result of the use of i) a ligand that is long enough to coordinate to silver via the $\mathrm{O}$-atoms in a wrapping modus, and ii) a non-coordinating anion, $\mathrm{PF}_{6}{ }^{-}$. We have previously found that the coordination capacities of the anions play a major role in the outcome of the solid-state structure. $^{14}$

The adjacent pyridine rings in the broken helix are at a distance of $4.55 \AA$ (measured between the centroids), which is too far for $\pi-\pi$ interactions. ${ }^{20}$ Viewed along the $z$-axis, 4 forms channels separated by $\mathrm{PF}_{6}$-anions (Fig. 13, ESI Fig. S3). A structurally similar silver compound has been proposed by Hosseini et al. ${ }^{21}$ in which ligands from tetraethylene glycol or hexaethylene glycol bis-nicotinate form a double helical arrangement, with $\mathrm{PF}_{6}{ }^{-}$anions occupying the empty space. We have obtained similar double-helical structures with shorter ligands compared to Hosseini et al., under conditions that allow the anion to fill the remaining coordination site at the silver ion, involving however binding anions such as nitrate and triflate. ${ }^{3}$ Shorter ligands and the use of a non-coordination anion then lead to metallacycle formation rather than double helical coordination polymers. ${ }^{22}$ Thus, the role of the anion is crucial in these cases and may have an opposite effect depending on the length of the ligands used.

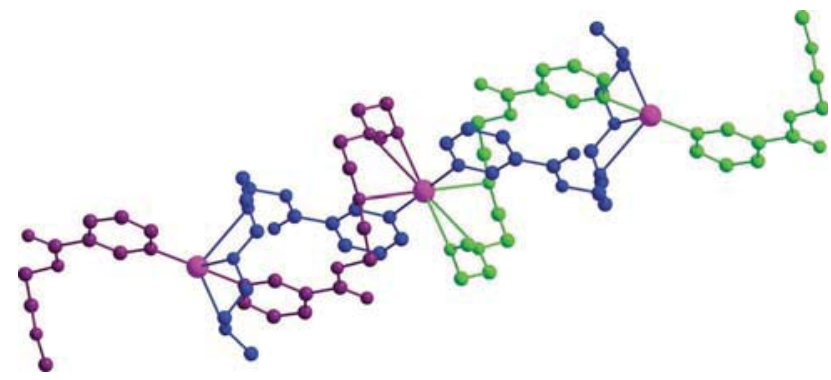

Fig. 12 Broken helix of the silver coordination polymer of 4, with the ligands in different colors (hydrogen atoms and counter ions are omitted for clarity).

\section{Discussion}

Although the complexes with $\mathbf{L} 1$ but different anions have an almost identical coordination sphere around the silver cation, the arrangement of their building blocks is different. Specifically, $\mathbf{1}$ forms a $1 \mathrm{D}$ coordination polymer via the nitrate group, as well as 2 which forms dimers that are connected over the triflate ion as well as via $\pi-\pi$-interactions. These dimers are arranged in stacks, but do not form a coordination polymer. $\mathbf{3}$, which is based on the medium long ligand $\mathbf{L 2}$, is completely different in that the cis arrangement of the side chains (both glycol chains are on the same side of the molecule) causes the molecule to be asymmetric. Hence, the molecules arrange in stacks, where they are held together via $\pi-\pi$-stacking, forming a kind of channel system. In 4, the main feature is that the silver ions are also coordinated by the ethylene glycol chains. This double coordination of the silver ion at both coordination sites of the ligand molecule affords a helical arrangement, leading to formation of a "broken" double helix (overview of packings, ESI Fig. S4). Although the structures have four completely different arrangements, their bond lengths are similar. Table 1 shows the different distances and angles of the complexes, the $\mathrm{Ag} \cdots \mathrm{Ag}$ distances are measured using the second silver atom which is generated by symmetry operation.

The $\mathrm{Ag}-\mathrm{N}$ distances are almost identical to each other, with the largest deviation being only about $0.04 \AA$. The angles of the $\mathrm{N}-\mathrm{Ag}-\mathrm{N}$ bonds for the $\mathbf{L} 1$ and $\mathbf{L} 2$ ligands were between $160^{\circ}$ and $171^{\circ}$. The $\mathrm{N}-\mathrm{Ag}-\mathrm{N}$ angle of $180^{\circ}$ in $\mathbf{4}$ is induced by symmetry. Specifically, $\mathbf{4}$ crystallizes in the monoclinic space group $C 2 / c$ with an inversion point on the silver ion $(0.5,0,0.5)$, while the other structures all exhibit a triclinic space group $(P \overline{1})$.

In 2 and 3, the $\mathrm{Ag}-\mathrm{Ag}$ distances are $3.2458 \AA$ and $3.404 \AA$, respectively. This is at best a weak interaction. ${ }^{18}$ In $\mathbf{1}$, the nitrate anions act as bridging linkers between the chains and cap the metal ions. In 4, the silver ions are completely surrounded by oxygen and nitrogen atoms. The $\mathrm{Ag}-\mathrm{O}$ distances are $3.14 \AA$ long on average, which is at the upper limit of the values that have been reported to date (2.317-3.164 å). ${ }^{17} \pi-\pi$ Stacking can be observed for compounds $\mathbf{1}, \mathbf{2}$, and $\mathbf{3}$. Owing to the intercalated arrangement of the ligand in $\mathbf{3}$, the distance of the pyridine rings is very short. All compounds show an offset of the pyridine-ring.

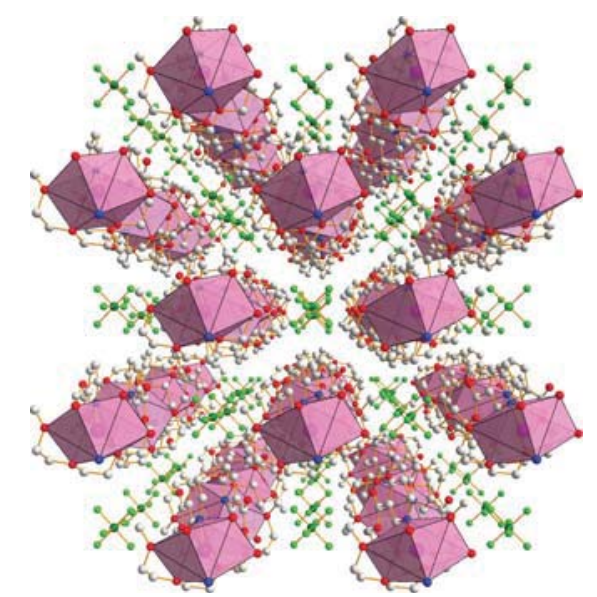

Fig. 13 View of the packing along the $z$-axis with channel formation. 
Table 1 Different bond lengths and angles in $\AA$ and ${ }^{\circ}$, respectively. The last row shows the data found for the similar structural motifs in the Cambridge Database for the given bond lengths and angles

\begin{tabular}{|c|c|c|c|c|c|c|}
\hline & $\mathrm{Ag}-\mathrm{N}$ & $\mathrm{Ag} \cdots \mathrm{Ag}$ & $\mathrm{N}-\mathrm{Ag}-\mathrm{N}\left({ }^{\circ}\right)$ & Ag-O (nitrate) & Ag-O(triflate $)$ & $\overline{\mathrm{Ag}-\mathrm{O} \text { (ligand) }}$ \\
\hline \multirow[t]{2}{*}{1} & $2.184(15)$ & $4.395(2)$ & $160.9(5)$ & $2.692(6)$ & & \\
\hline & $2.187(15)$ & & & $2.765(1)$ & & \\
\hline \multirow[t]{2}{*}{2} & $2.143(17)$ & $3.2458(8)$ & $171.92(6)$ & $2.899(2)$ & & \\
\hline & $2.144(18)$ & & & $3.032(2)$ & & \\
\hline \multirow[t]{2}{*}{3} & $2.136(12)$ & $3.405(2)$ & $166.4(4)$ & & $2.684(2)$ & \\
\hline & $2.165(12)$ & & & & & \\
\hline \multirow[t]{3}{*}{4} & $2.161(2)$ & $\sim 9.2$ & 180 & & & $3.116(2)$ \\
\hline & & & & & & $3.126(2)$ \\
\hline & & & & & & $3.177(2)$ \\
\hline CSD & $1.91-2.98$ & $2.63-3.91$ & $62.6-180.0$ & $2.18-3.58$ & $2.14-3.02$ & $2.31-3.16$ \\
\hline
\end{tabular}

However, no $\mathrm{Ag}-\pi$ interactions are observed in these compounds.

Preliminary test of evaporation and deposition of compounds 2 and 4 via metal-organic vapor deposition (MOCVD) on a Si substrate

One of our interests is to determine if the silver compounds have the ability to evaporate on a substrate. Indeed, such a property would be of interest for possible deposition on implants. Therefore, we performed a test using a MOCVD chamber to determine if our compounds would evaporate. Compounds 2 and 4 were selected for these tests since it was possible to easily scale up the reaction and obtain several grams of these materials.

In MOCVD, the light brown powder of the bulk material of $\mathbf{2}$ starts to evaporate at around $80^{\circ}$, but only at a slow rate $\left(0.2 \mathrm{k}^{-1} \mathrm{~s}^{-1}\right)$. At $100{ }^{\circ} \mathrm{C}$, the powder melts, still evaporating. After a slow temperature increase to $200{ }^{\circ} \mathrm{C}, \mathbf{2}$ decomposed to a black product (PXRD shows the presence of metallic silver and $\mathrm{Ag}_{2} \mathrm{O}$ ). An approximately $100 \mathrm{~nm}$ thick layer could be grown on the silicon plate.

As shown in Fig. 14, SEM revealed the presence of a regular surface with a small droplets-like structure $(1 \mu \mathrm{m})$. The droplets are not liquid, but until now, it was not possible to determine the chemical composition. This droplet formation could be possibly avoided by using another substrate for the coating.

The regular arrangements of the evaporated product indicate that it has the potential for use as future coatings on implant materials. However, the low evaporation rate of the complex is a problem; accordingly, various evaporation conditions should be investigated to optimize this characteristic.

During the MOCVD process, 4 evaporates between $90{ }^{\circ} \mathrm{C}$ and $100{ }^{\circ} \mathrm{C}$ at a rapid rate $\left(0.5-0.8 \mathrm{k}^{\circ} \mathrm{s}^{-1}\right)$. The film obtained using this method was measured by SEM (Fig. 15). A smooth film with small holes on the surface on the MOCVD was seen. The size of the holes was approximately $1 \mu \mathrm{m}$. A small crack is visible in the selected area, giving an impression of the thickness of the film.

Overall, the silver compounds were found to be evaporable at low pressures and low temperatures. Further investigations of the obtained films are necessary to determine if the complete complexes evaporate or if decomposition and rearrangement processes occur.

\section{Experimental}

\section{Synthesis of $\mathrm{L} 1\left[\mathrm{C}_{9} \mathrm{H}_{11} \mathrm{O}_{3} \mathrm{~N}\right]$}

Oxalylchloride (5.1 ml, $0.06 \mathrm{~mol}, 1.5 \mathrm{eq})$ was dropped slowly into a suspension of nicotinic acid ( $5 \mathrm{~g}, 0.04 \mathrm{~mol}, 1 \mathrm{eq})$ in

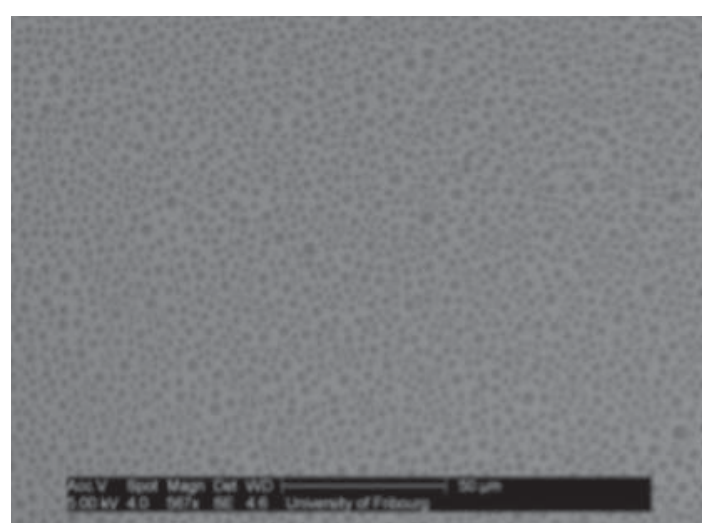

Fig. 14 Droplet formation of the residue of 2 after MOCVD: 587x $(50 \mu \mathrm{m})$ and $2267 \mathrm{x}(10 \mu \mathrm{m})$.

dichloromethane $(100 \mathrm{ml})$. The mixture was then stirred overnight at room temperature. The solution was filtered and the solid was dried under reduced pressure.

The white nicotinic acid chloride obtained by this process (5.76 g, $0.04 \mathrm{~mol}, 1 \mathrm{eq})$ was suspended in toluene $(100 \mathrm{ml})$, after which triethylamine $(8.6 \mathrm{ml}, 0.06 \mathrm{~mol}, 1.5 \mathrm{eq})$ was slowly added. The reaction mixture was then refluxed for $10 \mathrm{~min}$ and allowed to cool. Next, a solution of monoethylene glycol monomethylether $(9.10 \mathrm{ml}, 0.05 \mathrm{~mol}, 1 \mathrm{eq})$ in toluene was slowly added and the mixture was again refluxed for $6 \mathrm{~h}$ at $130{ }^{\circ} \mathrm{C}$. The brown liquid was stirred overnight at room temperature, after which

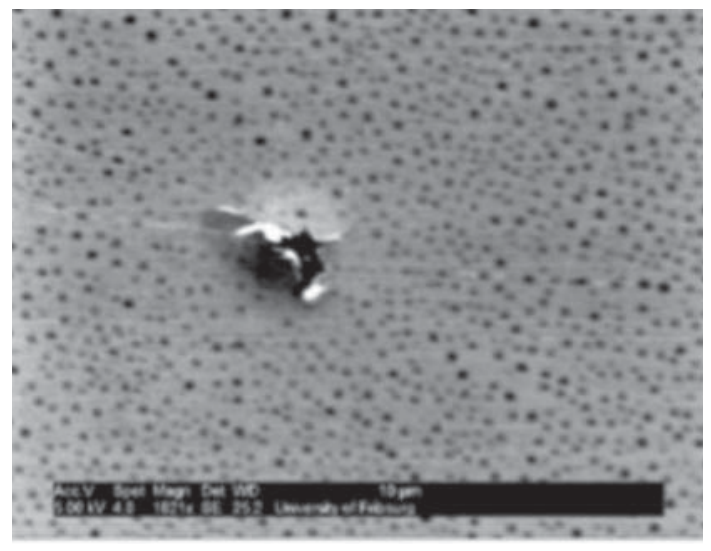

Fig. 15 Close up $(1621 x, 10 \mu \mathrm{m})$ of the thin film of 4 that was evaporated on a Si substrate (a crack of the film is visible on the picture). 
dichloromethane $(80 \mathrm{ml})$ was added, the mixture was extracted, and the layers were separated. The organic phase was washed twice with water $200(\mathrm{ml})$. The organic phase was subsequently dried over $\mathrm{MgSO}_{4}$ and filtered, after which the solvent was removed under reduced pressure to yield a yellow liquid (yield $75 \%$ ). ${ }^{1} \mathrm{H}$ NMR (360 MHz, $\mathrm{CDCl}_{3}, \mathrm{TMS}$, values given in $\left.\mathrm{ppm}\right): \delta$ $9.23(\mathrm{~s}, 1 \mathrm{H}), 8.32(\mathrm{dd}, 1 \mathrm{H}, J=3.2 \mathrm{~Hz}, J=4.7 \mathrm{~Hz}), 7.40(\mathrm{dt}, 1 \mathrm{H}$, $J=1.87 \mathrm{~Hz}, \mathrm{~Hz}, J=7.9 \mathrm{~Hz}), 7.36(\mathrm{dd}, 1 \mathrm{H}, J=2.49 \mathrm{~Hz}, J=$ $7.49 \mathrm{~Hz}), 4.49$ (t, 2H, $J=4.7 \mathrm{~Hz}), 3.72(\mathrm{t}, 2 \mathrm{H}, J=4.7 \mathrm{~Hz}), 3.40$ (s, 3H). ${ }^{13} \mathrm{C}$ NMR (90 MHz, $\mathrm{CDCl}_{3}$, TMS, values given in ppm): $\delta 165.1$ (C6), 153.4 (C2), 150.9 (C1), 137.1 (C4), 126.1 (C4), 123.1 (C3), 70.3 (C7), 64.3 (C8), 58.9 (C9). FTIR $\left(\mathrm{cm}^{-1}\right)$ : 3080 (C=C), 2985 and $2887(\mathrm{C}-\mathrm{C}), 1720(\mathrm{C}=\mathrm{O}), 1591(\mathrm{C}=\mathrm{N}), 1278(\mathrm{RCOO})$ 1114 (C-O). Element. anal. calcd. for $\left(\mathrm{C}_{9} \mathrm{H}_{11} \mathrm{NO}_{3}\right.$, with contamination of $0.75 \% \mathrm{H}_{2} \mathrm{O}$ and $0.25 \%$ of toluene) (\%): $\mathrm{C}$, 59.09; H, 6.20; N, 6.14. Found; C, 58.87; H, 6.59; N, 6.54.

\section{Synthesis of $\mathrm{L} 2\left[\mathrm{C}_{11} \mathrm{H}_{15} \mathrm{O}_{4} \mathrm{~N}\right]$}

The same procedure was then used to prepare L1, but monoethylene glycol was replaced with diethylene glycol monomethylether (6 ml, $0.05 \mathrm{~mol}, 1 \mathrm{eq})$ (yield $82 \%) .{ }^{1} \mathrm{H}$ NMR (360 MHz, $\mathrm{CDCl}_{3}$, TMS, values given in ppm): $\delta 9.20(\mathrm{~s}, 1 \mathrm{H})$, $8.74(\mathrm{dd}, 1 \mathrm{H}, J=3.19 \mathrm{~Hz}, J=4.9 \mathrm{~Hz}), 8.28(\mathrm{dt}, 1 \mathrm{H}, J=1.82 \mathrm{~Hz}$, $\mathrm{Hz}, J=7.9 \mathrm{~Hz}), 7.35(\mathrm{dd}, 1 \mathrm{H}, J=2.95 \mathrm{~Hz}, J=4.76 \mathrm{~Hz}), 4.49(\mathrm{t}$, $2 \mathrm{H}, J=4.7 \mathrm{~Hz}), 3.82(\mathrm{t}, 2 \mathrm{H}, J=4.7 \mathrm{~Hz}), 3.65(\mathrm{~m}, 2 \mathrm{H}), 3.52(\mathrm{~m}$, $2 \mathrm{H}, J=4.7 \mathrm{~Hz}), 3.34$ (s, 3H). FTIR $\left(\mathrm{cm}^{-1}\right): 3072(\mathrm{C}=\mathrm{C}), 2889$ (C-C), $1722(\mathrm{C}=\mathrm{O}), 1589(\mathrm{C}=\mathrm{N}), 1272(\mathrm{RCOO}) 1105(\mathrm{C}-\mathrm{O})$. Element. anal. calcd. for $\left(\mathrm{C}_{11} \mathrm{H}_{15} \mathrm{O}_{4} \mathrm{~N}\right)(\%): \mathrm{C}, 58.32 ; \mathrm{H}, 6.74 ; \mathrm{N}$, 6.14. Found; C, 58.64; H, 6.72; N, 6.22.

\section{Synthesis of $\mathrm{L3},\left[\mathrm{C}_{13} \mathrm{H}_{19} \mathrm{O}_{5} \mathrm{~N}\right]$}

The same procedure was then used then for the synthesis of L1, but monoethylene glycol was replaced with triethylene glycol monomethylether (10.8 ml, $0.05 \mathrm{~mol}, 1 \mathrm{eq}$ ) (yield $80 \%) .{ }^{1} \mathrm{H}$ NMR (360 MHz, $\mathrm{CDCl}_{3}, \mathrm{TMS}$, values given in ppm): $\delta 9.09(\mathrm{~s}, 1 \mathrm{H})$, $8.63(\mathrm{~s}, 1 \mathrm{H}), 8.17(\mathrm{~m} \mathrm{1H}), 7.26(\mathrm{~m}, 1 \mathrm{H}), 4.37(\mathrm{t}, 2 \mathrm{H}, J=4.5 \mathrm{~Hz})$, $3.71(\mathrm{t}, 2 \mathrm{H}, J=4.5 \mathrm{~Hz}), 3.58-3.52(\mathrm{~m}, 6 \mathrm{H}), 3.39(\mathrm{t}, 2 \mathrm{H}, J=$ $4.4 \mathrm{~Hz}$ ), 3.39 (s, 3H). ${ }^{13} \mathrm{C} \mathrm{NMR}\left(90 \mathrm{MHz}, \mathrm{CDCl}_{3}\right.$, TMS, values given in ppm): $\delta 164.8$ (C6), 153.1 (C3), $150.6(\mathrm{C} 2), 136.74(\mathrm{C} 5)$, 125.64 (C1), 122.92 (C4), 71.53 (C12), 70.32 (C9, C10, C11), $68.66(\mathrm{C} 8), 64.14(\mathrm{C} 7), 58.62(\mathrm{C} 13)$. FTIR $\left(\mathrm{cm}^{-1}\right)$ : $3043(\mathrm{C}=\mathrm{C})$, $2864(\mathrm{C}-\mathrm{C}), 1722(\mathrm{C}=\mathrm{O}), 1589(\mathrm{C}=\mathrm{N}), 1278(\mathrm{RCOO}) 1107$ (C-O). UV-VIS (in chloroform $\lambda_{\max }, \mathrm{nm}$ ): $212 \mathrm{~nm}, 261 \mathrm{~nm}$, $317 \mathrm{~nm}$. Element. anal. calcd. for $\left(\mathrm{C}_{13} \mathrm{H}_{19} \mathrm{O}_{5} \mathrm{~N}\right)(\%)$ : C, 58.03; $\mathrm{H}$, 6.89; N, 4.98. Found; C, 57.98; H, 7.11; N, 5.20.

\section{$1,\left[\operatorname{Ag}\left(\mathrm{C}_{9} \mathrm{H}_{11} \mathrm{O}_{3} \mathrm{~N}\right)_{2}\left(\mathrm{NO}_{3}\right)\right]$}

$\mathrm{AgNO}_{3}(0.084 \mathrm{~g}, 0.5 \mathrm{mmol}, 1 \mathrm{eq})$ and $\mathbf{L 1}(0.181 \mathrm{~g}, 1 \mathrm{mmol}, 2 \mathrm{eq})$ were dissolved together in $20 \mathrm{ml}$ ethanol and reacted overnight at room temperature. Colorless crystals of $\mathbf{1}$ suitable for single crystal X-ray structure determination were obtained within a week after slow evaporation of the solution (yield 65\%). ${ }^{1} \mathrm{H}$ NMR (360 MHz, DMSO, values given in ppm): $\delta 9.12(\mathrm{~s}, 1 \mathrm{H})$, $8.35(\mathrm{dd}, 1 \mathrm{H}, J=1.3 \mathrm{~Hz}, J=4.8 \mathrm{~Hz}), 8.33(\mathrm{dt}, 1 \mathrm{H}, J=2.2 \mathrm{~Hz}$, $\mathrm{Hz}, J=7.9 \mathrm{~Hz}), 7.63(\mathrm{dd}, 1 \mathrm{H}, J=4.9 \mathrm{~Hz}, J=7.9 \mathrm{~Hz}), 4.43(\mathrm{t}$, $2 \mathrm{H}, J=4.5 \mathrm{~Hz}), 3.68(\mathrm{t}, 2 \mathrm{H}, J=4.5 \mathrm{~Hz}), 3.3(\mathrm{~s}, 3 \mathrm{H}) .{ }^{13} \mathrm{C} \mathrm{NMR}$ (90 MHz, DMSO, values given in ppm): $\delta 164.6$ (C6), 154.1 (C2),
150.4 (C1), 137.4 (C4), 125.9 (C4), 124.4 (C3), 69.8 (C7), 64.4 (C8), 58.3 (C9). FTIR $\left(\mathrm{cm}^{-1}\right): 3078(\mathrm{C}=\mathrm{C}), 2827(\mathrm{C}-\mathrm{C}), 1720$ $(\mathrm{C}=\mathrm{O}), 1602(\mathrm{C}=\mathrm{N}), 1278(\mathrm{RCOO}), 1109(\mathrm{C}-\mathrm{O})$. Element. anal. calcd. for $\left(\mathrm{C}_{18} \mathrm{H}_{22} \mathrm{AgN}_{3} \mathrm{O}_{9}\right)$ (\%): C, 40.58; H, 4.21; N, 8.01. Found; C, 40.60; H, 4.17; N, 7.90.

\section{2, $\left[\mathrm{Ag}\left(\mathrm{C}_{9} \mathrm{H}_{11} \mathrm{O}_{3} \mathrm{~N}\right)_{2}\left(\mathrm{SO}_{3} \mathrm{CF}_{3}\right)\right]$}

Crystals of $\mathbf{2}$ were then obtained with the same reaction procedure used for compound 1, but using $\mathrm{AgSO}_{3} \mathrm{CF}_{3}(0.127 \mathrm{~g}, 0.5 \mathrm{mmol}$, 1 eq) (yield 62\%). The crystals are colorless, while the bulk material shows a very slight brownish coloration. ${ }^{1} \mathrm{H}$ NMR (360 MHz, DMSO, TMS, values given in ppm): $\delta 9.29$ (s, 1H), 9.0 $(\mathrm{dd}, 1 \mathrm{H}, J=3.63 \mathrm{~Hz}, J=5.23 \mathrm{~Hz}), 7.40(\mathrm{dt}, 1 \mathrm{H}, J=1.6 \mathrm{~Hz}, J=$ $7.9 \mathrm{~Hz}), 7.65(\mathrm{dd}, 1 \mathrm{H}, J=2.49 \mathrm{~Hz}, J=7.9 \mathrm{~Hz}), 4.54(\mathrm{t}, 2 \mathrm{H}, J=$ $4.6 \mathrm{~Hz}), 3.74(\mathrm{dd}, 2 \mathrm{H}, J=4.9 \mathrm{~Hz}, J=9.5 \mathrm{~Hz}), 3.43(\mathrm{~s}, 3 \mathrm{H}) .{ }^{13} \mathrm{C}$ NMR (90 MHz, DMSO, values given in ppm): $\delta 164.4$ (C6), 153.9 (C2), 150.2 (C1), 137.4 (C4), 125.8 (C4), 124.1 (C3), 71.1 (C7), 64.4 (C8), 57.9 (C9). FTIR $\left(\mathrm{cm}^{-1}\right): 3111$ and $3053(\mathrm{C}=\mathrm{C}), 2896(\mathrm{C}-\mathrm{C})$, $1726(\mathrm{C}=\mathrm{O}), 1600(\mathrm{C}=\mathrm{N}), 1284(\mathrm{RCOO}), 1205(\mathrm{C}-\mathrm{F}), 1049(\mathrm{~S}=\mathrm{O})$, 1022 (C-O). MOCVD: $80^{\circ}$ at $10^{-5}$ mbar.

\section{3, $\left[\left(\operatorname{Ag}\left(\mathrm{C}_{11} \mathrm{H}_{15} \mathrm{O}_{4} \mathrm{~N}\right)_{2}\left(\mathrm{SO}_{3} \mathrm{CF}_{3}\right)\right]\right.$}

Colorless crystals of $\mathbf{3}$ were obtained with the same reaction procedure used for compound 1, but using $\mathrm{AgSO}_{3} \mathrm{CF}_{3}(0.127 \mathrm{~g}$, $0.5 \mathrm{mmol}, 1 \mathrm{eq})$ and $\mathbf{L 2}$ (0.225 g, $1 \mathrm{mmol}, 2$ eq) (yield $80 \%) .{ }^{1} \mathrm{H}$ NMR (360 MHz, DMSO, values given in ppm): $\delta 9.12(\mathrm{~s}, 1 \mathrm{H})$, $8.84(\mathrm{~d}, 1 \mathrm{H}, J=3.8 \mathrm{~Hz}), 8.32(\mathrm{dt}, 1 \mathrm{H}, J=1.9 \mathrm{~Hz}, J=8.2 \mathrm{~Hz})$, $7.63(\mathrm{dd}, 1 \mathrm{H}, J=2.9 \mathrm{~Hz}, J=4.9 \mathrm{~Hz}), 4.45(\mathrm{t}, 2 \mathrm{H}, J=4.6 \mathrm{~Hz})$, 3.67 (t, 2H, $J=4.6 \mathrm{~Hz}), 3.35$ (broad, $4 \mathrm{H}), 3.31$ (s, 3H). ${ }^{13} \mathrm{C} \mathrm{NMR}$ (90 MHz, DMSO, values given in ppm): $\delta 164.8$ (C6), 154.3 (C3), 150.6 (C2), 137.7 (C5), 126.2 (C1), 124.8 (C4), 70.1 (C10), 68.3 (C8), 66.5 (C9), 64.7 (C7), 58.5 (C11). FTIR $\left(\mathrm{cm}^{-1}\right)$ : $3112(\mathrm{C}=\mathrm{C})$, 2894 and $2955(\mathrm{C}-\mathrm{C}), 1752(\mathrm{C}=\mathrm{O}), 1608$ (very small, $\mathrm{C}=\mathrm{N}), 1281$ (RCOO) 1025 (C-O). UV-VIS: $263 \mathrm{~nm}$. Element. anal. calcd. for $\left(\mathrm{C}_{23} \mathrm{H}_{30} \mathrm{AgF}_{3} \mathrm{~N}_{2} \mathrm{O}_{11} \mathrm{~S}^{*} \mathrm{H}_{2} \mathrm{O}\right)$ (\%), the bulk material has one supplementary water molecule per formula unit: $\mathrm{C}, 37.56$; $\mathrm{H}$, 3.94; N, 3.65. Found; C, 37.14; H, 4.61; N, 3.77.

\section{4, $\left.\left[\mathrm{Ag}\left(\mathrm{C}_{13} \mathrm{H}_{19} \mathrm{O}_{5} \mathrm{~N}\right)_{2}\right] \mathrm{PF}_{6}\right]$}

Crystals of 4 were obtained with the same reaction procedure for compound 1, but using $\mathrm{AgPF}_{6}(0.26 \mathrm{~g}, 0.5 \mathrm{mmol}, 1 \mathrm{eq})$ and $\mathbf{L 3}$ (0.69 g, $1 \mathrm{mmol}, 2$ eq) (yield 55\%). ${ }^{1} \mathrm{H}-\mathrm{NMR}$ (360 MHZ, DMSO, values given in ppm): $\delta 9.42$ (broad, $1 \mathrm{H}), 8.93$ (broad, $1 \mathrm{H}), 8.37$ (d, 1H), 7.47 (broad, 1H), $4.53(\mathrm{t}, 2 \mathrm{H}, J=3.4 \mathrm{~Hz}), 3.86(\mathrm{t}, 2 \mathrm{H}$, $J=3.4 \mathrm{~Hz}), 3.67(\mathrm{~m}, 6 \mathrm{H}), 3.53(\mathrm{t}, 2 \mathrm{H}, J=3.4 \mathrm{~Hz}), 3.36(\mathrm{~s}, 3 \mathrm{H})$. ${ }^{13} \mathrm{C}$ NMR (90 MHz, DMSO, values given in ppm): $\delta 164.9$ (C6), 153.2 (C3), 150.7 (C2), 137.03 (C5), 125.7 (C1), 123.2 (C4), 70.5 (C9, C10), 68.9 (C8), 64.3 (C7). FTIR $\left(\mathrm{cm}^{-1}\right)$ : $3311(\mathrm{OH}), 3078$ $(\mathrm{C}=\mathrm{C}), 2970$ and $2871(\mathrm{C}-\mathrm{C}), 1724(\mathrm{C}=\mathrm{O}), 1583$ (very small, $\mathrm{C}=\mathrm{N}), 1292$ (RCOO) 1083 and 1051 (C-O). UV-VIS (in chloroform $\lambda_{\max }, \mathrm{nm}$ ): 226 and $263 \mathrm{~nm}$. Element. anal. calcd. for $\left(\mathrm{C}_{26} \mathrm{H}_{38} \mathrm{AgF}_{6} \mathrm{~N}_{2} \mathrm{O}_{10} \mathrm{P}^{*} \mathrm{H}_{2} \mathrm{O}\right)(\%)$, the bulk material has one supplemental water molecule per formula unit: $\mathrm{C}, 38.16 ; \mathrm{H}, 4.60$; N, 3.38. Found; C, 38.56; H, 4.98; N, 3.46.

The crystal parameters of all four compounds used in the unit cell determination, and structure refinement parameters, are summarized in Table 2. 
Table 2 Crystallographic data for complexes 1-4

\begin{tabular}{|c|c|c|c|c|}
\hline & 1 & 2 & 3 & 4 \\
\hline Formula sum & $\mathrm{C}_{18} \mathrm{H}_{22} \mathrm{AgN}_{3} \mathrm{O}_{9}$ & $\mathrm{C}_{19} \mathrm{H}_{22} \mathrm{AgF}_{3} \mathrm{~N}_{2} \mathrm{O}_{9} \mathrm{~S}$ & $\mathrm{C}_{23} \mathrm{H}_{30} \mathrm{AgF}_{3} \mathrm{~N}_{2} \mathrm{O}_{11} \mathrm{~S}$ & $\mathrm{C}_{26} \mathrm{H}_{38} \mathrm{AgF}_{6} \mathrm{~N}_{2} \mathrm{O}_{10} \mathrm{P}$ \\
\hline Formula weight & 532.26 & 619.32 & 707.42 & 791.42 \\
\hline space group & $P \overline{1}$ & $P \overline{1}$ & $P \overline{1}$ & $C 2 / c$ \\
\hline$T,{ }^{\circ} \mathrm{C}$ & $200(2)$ & $200(2)$ & $200(2)$ & $200(2)$ \\
\hline$a l \AA$ & $7.9771(16)$ & $8.6012(17)$ & $6.9425(14)$ & $12.512(3)$ \\
\hline bli̊ & $8.8183(18)$ & $9.789(2)$ & $14.521(3)$ & $14.026(3)$ \\
\hline$c l \AA$ & $15.2521(3)$ & $15.478(3)$ & $15.221(3)$ & $18.400(4)$ \\
\hline$a$, deg & $88.62(3)$ & $80.60(3)$ & $65.67(3)$ & 90 \\
\hline$b, \operatorname{deg}$ & $79.86(3)$ & $85.47(3)$ & $85.39(3)$ & $90.63(3)$ \\
\hline$g$, deg & $76.96(3)$ & $66.02(3)$ & $89.13(3)$ & 90 \\
\hline$V, \mathrm{~A}^{3}$ & $1028.7(4)$ & $1174.7(4)$ & $1393.4(5)$ & $3229.1(11)$ \\
\hline$r_{\text {calc }}, \mathrm{g} \mathrm{cm}^{-3}$ & 1.718 & 1.751 & 1.686 & 1.628 \\
\hline$m, \mathrm{~cm}^{-1}$ & 1.037 & 1.023 & 0.879 & 0.764 \\
\hline $\mathbf{Z}$ & 2 & 2 & 2 & 4 \\
\hline $\mathbf{R}^{23}$ & 0.1448 & 0.0235 & 0.1333 & 0.044 \\
\hline $\mathbf{w R}_{2}$ & 0.3478 & 0.054 & 0.3268 & 0.1039 \\
\hline Completeness $\theta$ & 99.4 & 99.2 & 98.5 & 99.4 \\
\hline Goodness-of-fit F2 & 1.173 & 1.034 & 1.06 & 1.079 \\
\hline Reflections collected/unique & $17052 / 4628$ & $10682 / 4946$ & $20181 / 5647$ & $22976 / 3403$ \\
\hline$F(000)$ & 540 & 624 & 720 & 1616 \\
\hline
\end{tabular}

\section{Conclusions}

Three new ligands and four new coordination compounds were prepared and characterized. The ligands were generated from nicotinic acid and methyl ethylene glycol chains of different lengths. The ligands were reacted with different silver salts, and the crystal structures showed a range of different coordination and packing behaviors depending on the salt and the increasing ligand length. Two of the complexes were shown to evaporate at moderate temperatures with moderate to good evaporation rates, forming regular thin films on a silicon substrate. While one compound decomposes, the other seems to be deposited on the substrate.

\section{Acknowledgements}

The authors thank the Swiss National Science Foundation, FriMat, and the University of Fribourg for their generous support.

\section{References}

1 (a) H. W. Roesky and M. Andruh, Coord. Chem. Rev., 2003, 236, 9; (b) C. Janiak, Dalton Trans., 2003, 2781.

2 A. J. Blake, N. R. Champness, P. Hubberstey, W. S. Li, M. A. Withersby and M. Schröder, Coord. Chem. Rev., 1999, 183, 117.

3 A. N. Khlobystov, A. J. Blake, N. R. Champness, D. A. Lemenovskii, A. G. Majouga, N. V. Zyk and M. Schröder, Coord. Chem. Rev., 2001, 222, 155.

4 D. A. Lemenovskii, W. S. Li and M. Schröder, J. Chem. Soc., Dalton Trans., 2000, 4285 .

5 G. Mahmoudi and A. Morsali, CrystEngComm, 2007, 9, 1062.

6 Y. B. Xie and X. H. Bu, J. Cluster Sci., 2004, 14, 471.

7 J. W. Steed, New J. Chem., 2005, 29, 90.

8 A. Y. Robin, J. L. Sague, A. Neels, T. Vig-Slenters and K. M. Fromm, Inorg. Chim. Acta, 2007, 360, 212.
9 D. M. L. Goodgame, D. A. Grachvogel, S. Holland, N. J. Long, A. J. P. White and D. J. Williams, J. Chem. Soc., Dalton Trans., 1999, 3473 .

10 (a) K. M. Fromm and A. Y. Robin, Coord. Chem. Rev., 2006, 250, 2127; (b) A. Y. Robin, J. L. Sague and K. M. Fromm, CrystEngComm, 2006, 8, 403; (c) K. M. Fromm, J. L. Sagué and L. Mirolo, Macromol. Symp., 2010, 1, 75; (d) F. Gschwind, O. Sereda and K. M. Fromm, Inorg. Chem., 2009, 48, 10535; (e) A. Y. Robin, M. Meuwly, K. M. Fromm, H. Goesmann and G. Bernardinelli, CrystEngComm, 2004, 6, 336; all references in 14-16 and 22.

11 K. Nomiya, S. Takahashi, R. Noguchi, S. Nemoto, T. Takayama and M. Oda, Inorg. Chem., 2000, 39, 3301.

12 W. K. Jung, H. C. Koo, K. W. Kim, S. Shin, S. H. Kim and Y. H. Park, Appl. Environ. Microbiol., 2008, 74, 2171.

13 (a) D. Campoccia, L. Montanaro and C. R. Arciola, Biomaterials, 2006, 27, 2331; (b) J. W. Costerton, P. S. Stewart and E. P. Greenberg, Science, 1999, 284, 1318.

14 T. Vig-Slenters, J. L. Sagué, P. S. Brunetto, S. Zuber, A. Fleury, L. Mirolo, A. Y. Robin, M. Meuwly, O. Gordon, R. Landmann, A. U. Daniels and K. M. Fromm, Materials, 2010, 3(5), 3407.

15 T. Vig-Slenters, I. Hauser-Gerspach, A. U. Daniels and K. M. Fromm, J. Mater. Chem., 2008, 18, 5359.

16 O. Gordon, T. Vig-Slenters, P. S. Brunetto, A. E. Villaruz, D. E. Sturdevant, M. Otto, R. Landmann and K. M. Fromm, Antimicrob. Agents Chemother., 2010, 54(10), 4208.

17 Cambridge Database CCDC, ConQuest Version 1.11, March 2009.

18 P. Pyykkö, Chem. Rev., 1997, 97, 597.

19 (a) N. A. Plate and V. P. Shibaev, J. Polym. Sci., Macromol. Rev., 1974, 8, 117; (b) A. N. Lazar, O. Danylyuk, K. Suwinska and A. W. Coleman, New J. Chem., 2006, 30, 59.

20 M. O. Sinnokrot, E. F. Valeev and C. D. Sherrill, J. Am. Chem. Soc., 2002, 124, 10887.

21 A. Jouaiti, M. W. Hosseini and N. Kyritsakas, Chem. Commun., 2003, 472.

22 I. Chevrier, J. L. Sagué and K. M. Fromm, submitted.

23 The R-values for compound $\mathbf{1}$ and $\mathbf{3}$ remain high, due to a poor crystal quality and not strong diffraction. For compound $\mathbf{3}$ we assume that disordered solvent molecules (see also elemental analysis) are present in the structure. Nevertheless all atoms were treated anisotropically. 